\title{
Therapeutic Antibodies in Stroke
}

\author{
Chye Yun Yu • Gandi Ng • Ping Liao
}

Received: 14 July 2013 / Revised: 30 July 2013 / Accepted: 5 August 2013 / Published online: 16 August 2013

(C) The Author(s) 2013. This article is published with open access at Springerlink.com

\begin{abstract}
Immunotherapy represents an active area of biomedical research to treat cancer, autoimmune diseases, and neurodegenerative disorders. In stroke, recanalization therapy is effective in reducing brain tissue damage after acute ischemic stroke. However, the narrow time window restricts its application for the majority of stroke patients. There is an urgent need to develop adjuvant therapies such as immunotherapy, stem cell replacement, and neuroprotective drugs. A number of molecules have been targeted for immunotherapy in stroke management, including myelin-associated proteins and their receptors, $N$-methyl-D-aspartic acid receptors, cytokines, and cell adhesion molecules. Both active vaccination and passive antibodies were tested in animal models of acute ischemic stroke. However, the mechanisms underlying the efficacy of immunotherapy are different for each target protein. Blocking myelin-associated proteins may enhance neuroplasticity, whereas blocking adhesion molecules may yield neuroprotection by suppressing the immune response after stroke. Although results from animal studies are encouraging, clinical trials using therapeutic antibodies failed to improve stroke outcome due to severe side effects. It remains a challenge to generate specific therapeutic antibodies with minimal side effects on other organs and systems.
\end{abstract}

Keywords Antibody $\cdot$ Stroke $\cdot$ Immunotherapy

\section{Introduction}

Prophylactic vaccination is widely used and is proven effective against infectious diseases. More recently, much attention has been paid to immunotherapy for the treatment of other

C. Y. Yu $\cdot$ G. Ng $\cdot$ P. Liao $(\bowtie)$

Calcium Signaling Laboratory, National Neuroscience Institute,

11 Jalan Tan Tock Seng, Singapore 308433, Singapore

e-mail: ping_liao@nni.com.sg diseases such as cancer [1], autoimmune diseases [2], and neurodegenerative disorders [3]. Immunotherapy has great potential to be an effective adjuvant therapy. Due to the specificity of the immune response, harnessing the immune system to block specific signaling pathways provides a powerful tool for the treatment of disease.

Stroke is one of the most common causes of death worldwide and is a heavy burden on the health care system. Ischemic strokes constitute the majority of all strokes. Inflammation triggered after stroke is characterized by an orderly sequence of events involving different components of the brain. Right after arterial occlusion, release of reactive oxygen species triggers the coagulation cascade and activates complement, platelet, and endothelial cells. The white blood cell count and cytokines and inflammatory markers are increased within hours, followed by a marked immunodepression within 1-2 days, particularly in large strokes. Such changes in the systemic immunity lead to higher occurrence of infection in respiratory and urinary systems. As the ischemia progresses, toxic molecules such as excessive ATP and neurotransmitters are released into the extracellular space to trigger innate and adaptive immunity. With the increased permeability of the blood-brain barrier, autoimmunity is induced against the dead brain cells. Circulating $\mathrm{T}$ cells are sensitized to produce antibodies against antigens in central nervous system. Antigenpresenting cells are mobilized from the periphery to the ischemic brain and contribute to the destruction of brain tissues at the site of ischemic lesion. Autoimmunity may have long-term consequences on stroke survivors including dementia and brain atrophy. On the other hand, the immunosuppression after stroke may reduce the autoimmune attach on the brain by limiting the development of $\mathrm{T}$ cells. The detailed immunology after stroke was best reviewed in ref [4].

The most effective treatments for acute ischemic stroke are revascularization by thrombolysis, the dissolving of the clot, and embolectomy, the surgical removal of the clot. Tissue plasminogen activator (tPA), a thrombolytic agent approved 
by the FDA, is widely used to treat acute embolic or thrombotic stroke. However, the narrow therapeutic time window $(<4.5 \mathrm{~h}$ post-stroke) benefits only a minority of stroke patients. Reperfusion after this time window causes damage to brain tissue as deleterious biochemical events are triggered that antagonize the beneficial effects. Thus, the challenge for reperfusion therapy is to both protect brain tissue and extend the therapeutic time window [5].

Immunotherapy for stroke treatment attracts significant scientific attention. Numerous signaling pathways are altered after stroke insult. Blocking certain deleterious pathways may delay brain tissue damage and even widen the time window for revascularization therapy. Immunotherapy provides a novel type of adjuvant stroke therapy. The interaction of antibodies with cytotoxic molecules and their receptors could rescue cell viability or delay cell death. Current investigations of stroke immunotherapy include active immunization by inoculation with peptides and passive immunization by direct injection of antibody into the animals. Many molecules have been targeted for stroke therapy, and a number of antibodies have been developed. These molecules are primarily on the cell membrane or in the extracellular space where they are accessible to the antibodies. Middle cerebral artery occlusion (MCAO) is the most common animal model of focal ischemia. The efficacy of the blocking antibodies is evaluated in either transient or permanent MCAO models. Although most of the antibodies were effective in reducing brain damage in animal models of stroke, clinical trials for several antibodies failed due to poor patient outcomes. Here, we review the current understanding of immunotherapy, particularly the use of therapeutic antibodies, for stroke management.

\section{Myelin-Associated Proteins}

Myelin in the adult central nervous system (CNS) contains abundant growth-inhibitory molecules, including proteoglycans, Nogo-A, myelin-associated glycoprotein (MAG), versican V2, and oligodendrocyte myelin glycoprotein (Omgp) [6]. Disrupted myelin is often associated with deposits of immunoglobulin and activated complement, which may cause autoimmune diseases such as multiple sclerosis [7].

Nogo-A, a member of the reticulon family, is produced by oligodendrocytes [8] and is a potent inhibitor of axonal remodeling. Nogo-A interacts with the Nogo-66 receptor and inhibits neurite outgrowth after CNS injury [9]. The monoclonal antibody (IN-1) against Nogo-A was generated several years prior to the identification of Nogo-A [10]. Because Nogo-A plays an important role after CNS injury, a number of studies have aimed to block its functions by infusion of antibodies against Nogo-A or the Nogo-66 receptor after stroke.

Immunotherapy against Nogo-A in animal models of stroke was shown to enhance functional recovery by improving neuroplasticity. Application of anti-Nogo-A antibody via intracerebroventricular [11] or intrathecal routes [12] at 1 week after operation could hasten the recovery from neurological damage. In a permanent rat MCAO model, delayed treatment with anti-Nogo-A antibody ( 9 weeks after operation) enhanced sprouting and midline crossing of corticorubral axons to innervate the deafferented red nucleus [13]. Following MCAO, IN1-treated animals showed increased dendritic arborization and spine density in the lesioned hemisphere [14]. IN-1 also promoted formation of new efferent cortical projections [15].

As stroke commonly occurs in hypertensive or aging patients, anti-Nogo-A antibodies were tested in animals with hypertension or in aged animals. Again, the antibody exhibited great potential to enhance neuroplasticity after stroke, significant functional improvement was observed in hypertensive rats receiving anti-Nogo-A antibody after permanent MCAO [16]. In aged rats (18 months old), anti-Nogo-A therapy given 1 week after MCAO improved reference memory in the Morris water maze task [17]. Similar to anti-Nogo-A therapy, antibody against the Nogo-66 receptor was proven effective in reducing stroke-induced brain damage. The impaired forelimb function of rats that underwent MCAO was ameliorated after the implantation of a hydrogel carrying polyclonal antibodies against the Nogo-66 receptor. Neurons and neurofibers were also found within the gel providing evidence of neuronal migration and regeneration [18].

In contrast to the promising results of blocking Nogo-A or the Nogo-66 receptor, mice with a Nogo-A deletion displayed increased mortality and exacerbated neurological deficits after transient MCAO. A similar observation was made in rats that received anti-Nogo-A antibody immediately following stroke, indicating that Nogo-A may play an opposite role in cerebral damage during the hyperacute phase of stroke [19]. It is possible that in the hyperacute phase, tissue damage is more prominent than tissue repair. Thus, the time point to block Nogo-A function is critical, antibodies that inhibit Nogo-A function may yield better effect during neural regeneration in the later stages of stroke recovery. It is critical to identify the proper time point for anti-Nogo-A treatment in human patients, as the rodents have a different life span than humans. A human monoclonal anti-Nogo-A antibody (ATI355) from Novartis has been approved for clinical trials to treat acute spinal cord injury (Table 1. ClinicalTrials.gov Identifier: NCT00406016). The phase I clinical trial has been completed and no severe side effects were observed from more than 50 subjects. Thus, this antibody may potentially be used for the treatment of ischemic stroke in the future.

MAG is another molecule found in myelin that can inhibit neurite outgrowth after injury. In a MCAO rat model, both intracerebral and systemic administration of MAG neutralization antibody reduced the lesion area and improved motor function. The effect was attributed not only to the blockade of MAG protein but also to the protection of oligodendrocytes from oxidative stress-induced cell death [20]. 
Table 1 Clinical trials for stroke immunotherapy

\begin{tabular}{lllll}
\hline Target & Condition & Intervention & Phase & Description \\
\hline E-selectin & Ischemic stroke & E-selectin nasal spray & II & Terminated (NCT00012454) \\
E-selectin & Ischemic stroke & Recombinant human E-selectin & I & Not recruited (NCT00069069) \\
Nogo-A & Acute spinal cord injury & ATI355 (anti-Nogo-A) & I & Completed (NCT00406016) \\
ICAM-1 & Acute stroke & Enlimomab (anti-ICAM-1) & III & Completed (Enlimomab Acute Stroke Trial) \\
\hline
\end{tabular}

Omgp is important for nerve myelination in the CNS. Autoantibody against Omgp is believed to cause multiple sclerosis [21]. Active immunization was applied to test the role of Omgp in stroke progress. Nasal vaccination with Omgp peptides before MCAO induced an anti-inflammatory response against CNS myelin, a process that involves the induction of $\mathrm{CD}^{+} \mathrm{T}$ cells producing IL-10. As a result, the infarct volume decreased and functional recovery was enhanced [22].

\section{NMDA Receptor}

Glutamate is a major excitatory neurotransmitter in the brain. In ischemic stroke, cessation of cerebral blood flow depletes the brain of glucose and oxygen, leading to neuronal membrane depolarization and release of large amount of glutamate into the extracellular space. Glutamate binds to glutamate receptors, such as $N$-methyl-D-aspartic acid (NMDA) receptors and DL- $\alpha$-amino-3-hydroxy-5-methyl-4-isoxazole propionic acid (AMPA) receptors causing influx of $\mathrm{Na}^{+}$and $\mathrm{Ca}^{2+}$ ions into the cell. Excessive activation of glutamate receptor can result in cell death. Accordingly, glutamate receptors are a major target for neuroprotection in a wide range of CNS disorders. Extensive studies have been conducted on glutamate receptors to improve stroke therapy.

tPA is a serine protease that converts plasminogen into active plasmin, leading to fibrin blood clot degradation. Endogenous tPA is produced after a thrombus forms. Due to its ability to recanalize cerebral blood vessels, recombinant tPA is used for thrombolysis within $4.5 \mathrm{~h}$ after stroke onset. It is the only FDA-approved pharmacological agent for acute ischemic stroke therapy [23]. However, tPA treatment has severe side effects such as cerebral edema and hemorrhage. tPA interacts with and cleaves the GluN1 (NR1) subunit of NMDA receptor, resulting in $\mathrm{Ca}^{2+}$ influx that activates a cascade of cell death signals [24]. Accordingly, blocking the interaction of IPA with the NMDA receptor would reduce the side effects of tPA treatment. Immunotherapy with antibodies targeting the TPA binding site on the NMDA receptor was able to prevent neuronal death both in vitro and in vivo. Using the adeno-associated virus as a carrier, autoantibodies were generated against the GluN1 subunit of the NMDA receptor in rats. After vaccination, antibodies were able to pass through the blood-brain barrier (BBB) and reduced total infarct volume by $70 \%$ in a permanent MCAO model [25]. Importantly, the antibodies persisted for over 5 months in the rats, indicating that vaccination can potentially prevent stroke. In a separate study, direct injection of a fragment of the GluN1 subunit prevented tPA cleavage of the NMDA receptor, successfully reducing the infarct volume after permanent MCAO [26].

The NMDA receptor was also targeted for passive immunization to treat ischemic stroke. Antibodies were produced in vitro against the GluN1 subunit and injected into animals after MCAO. The antibodies successfully diffused into the infarct region and reduced the brain tissue injury and BBB leakage in combination with tPA treatment. Importantly, a longer therapeutic time window for tPA thrombolysis was achieved in the animal model [27].

These experiments suggest the possibility of using active immunization against the NMDA receptor as a preventive vaccination and passive immunization to extend the time window for tPA thrombolysis [28]. Unfortunately, immunotherapy targeting NMDA receptors has not been successful in clinical practice. Although a wealth of evidence indicates that blockade of glutamate receptors could lead to dramatic neuroprotection in animal models, clinical trials of glutamate receptor blockers have not achieved therapeutic outcome [29]. A possible reason for this failure could be that the beneficial effects of glutamate receptor block are overcome by the deleterious effects on healthy cells. In patients with anti-NMDAR encephalitis, autoantibodies against GluN1 subunit of NMDA receptor are associated with a number of psychiatric symptoms within a few days after onset [30]. These antibodies bind, cross-link, and internalize NMDA receptors, leading to a decrease of synaptic NMDA currents [31]. Thus, blocking NMDA receptors indiscriminately may cause severe damage to the healthy neurons in other regions of the brain.

\section{Cell Adhesion Molecules and Cytokines}

Inflammation has been suggested to participate in stroke pathophysiology. Inflammatory signaling is triggered immediately following the ischemic attack and plays a dynamic role in all stages of stroke. This process is initiated with an orderly inflammation response that leads to the activation of complement, platelets, and endothelial cells within the injured vasculature. 
The subsequent release of cytokines leads to leukocytes infiltration through the BBB and contributes to the tissue damage after stroke. Proper modulation of the immune response after stroke insult can help protect the injured tissue and promote functional recovery.

Recruitment of leukocytes and platelets to injured cerebral blood vessels is a highly coordinated process that involves various adhesion molecules on the surface of endothelial cells, leukocytes, and platelets. These adhesion molecules include the selectin family, intercellular adhesion molecule-1 (ICAM1 , also known as CD54), and $\beta 2$-integrins. Numerous studies have demonstrated that disruption of leukocyte function yielded beneficial effects on stroke pathology. For example, depletion of neutrophils by an anti-neutrophil monoclonal antibody significantly reduced free radical generation [32] and attenuated brain edema after ischemic reperfusion injury [33]. In this way, immunotherapy could serve a beneficial role by inhibiting leukocyte functions. Neutralization of the adhesion molecules by therapeutic antibodies can disrupt the interaction of leukocytes with the injured vascular wall, thereby reducing leukocyte infiltration. Numerous antibodies have been developed to target these adhesion molecules.

The selectin family is composed of E-, L-, and P-selectin. They are involved in the adhesion of leukocytes to endothelial cells and subsequent transmigration into the brain parenchyma. Upregulation of E- and P-selectin on the surface of activated endothelial cells occurs soon after ischemic onset [34]. Endothelial selectins bind to leukocytes with low affinity via glycoproteins expressed on leukocytes. Surface expression of P-selectin on platelets and L-selectin on leukocytes also facilitates platelet-leukocyte aggregation.

In a permanent MCAO rat model, pretreatment with monoclonal anti-P-selectin antibody reduced leukocyte infiltration. Regional cerebral blood flow was elevated in association with attenuation of cerebral infarction [35] and brain edema [36]. In a murine transient MCAO model, neutralization of E-selectin with a monoclonal antibody led to increased cerebral blood flow, reduced neutrophil accumulation at the injured site, and improved neuroprotection [37]. Active immunization targeting E-selectin was also effective in stroke management. In spontaneously hypertensive rats, immune tolerance by repeated nasal instillation of E-selectin antigen successfully prevented the development of both ischemic and hemorrhagic strokes by suppressed endothelial activation [38, 39]. A phase II clinical trial was conducted with E-selectin nasal spray in patients with a stroke history to test the safety and effectiveness of E-selectin in preventing the formation of blood clots that can cause stroke. This trial was terminated (Table 1. NCT00012454) and another phase I trial using recombinant human E-selectin to prevent secondary stroke has not yet opened for participant recruitment since 2006 (Table 1. NCT00069069).

The effects of blocking L-selectin are different from blocking E- or P-selectin. In a rabbit transient MCAO model, a humanized anti-L-selectin antibody failed to prevent neutrophil migration into the injured site and did not alleviate neuronal damage [40]. However, when used in combination with tPA in a similar animal model, anti-L-selectin antibody demonstrated a moderate reduction of brain damage, which was absent in animals treated with tPA alone [41]. Thrombolysis with tPA alters the coagulation status in stroke patients and could lead to hemorrhage. It is possible that the beneficial effects of blocking L-selectin depend on the altered coagulation environment after IPA treatment.

ICAM-1 is a member of the immunoglobulin superfamily that is expressed on the surface of endothelial cells. Various cytokines can stimulate the expression of ICAM-1 [42, 43]. $\beta 2$-Integrins are expressed on the surface of leukocytes; ICAM-1 is the ligand for $\beta 2$-integrins LFA-1 (CD11a/ CD18) and Mac-1 (CD11b/CD18). Interaction between $\beta 2$ integrins (LFA-1 and Mac-1) and ICAM-1 provides a firm adhesion between leukocytes and endothelium [43, 44]. In various animal models of transient ischemic stroke, blocking of ICAM-1 with antibodies reduced polymorphonuclear leukocyte infiltration and neurological damage [45-47]. Together with tPA treatment, application of anti-ICAM-1 enhanced the thrombolytic effect and extended the therapeutic window for tPA [48].

Interestingly, anti-ICAM-1 treatment showed beneficial effects in transient ischemic stroke models but not in permanent MCAO models [49]. A commercial murine monoclonal anti-ICAM-1 antibody (Enlimomab) has been used for the treatment of ischemic stroke. However, the phase III clinical trial showed that the fatality rate was significantly higher in the Enlimomab patient group than in the placebo group [50]. The negative effect was apparent on day 5 after treatment. The serious adverse events include fever, myocardial infarction, pulmonary edema, pneumonia, stroke-related deterioration, cardiac arrest, meningitis, cerebral edema, and intracranial hemorrhage.

Immunoblocking of the $\beta 2$-integrin Mac-1 effectively alleviated ischemic reperfusion damage in the liver and heart by reducing neutrophil infiltration [51-53]. A monoclonal antibody targeting Mac-1 (CD11b) achieved similar effects with decreased intraparenchymal neutrophils after transient ischemia-reperfusion $[54,55]$. In a rabbit thromboembolic stroke model, monoclonal antibody against CD18 successfully reduced intracranial pressure but had no effect on cerebral blood flow and infarction [56].

The production and release of pro-inflammatory cytokines within the CNS are hallmarks of tissue damage following stroke. They are intimately involved in both innate and adaptive immunity at various stages of stroke [4]. IL-8 is a potent chemoattractant for polymorphonuclear neutrophils [57, 58] that is upregulated after stroke $[59,60]$. The rat equivalent of IL-8, cytokine-induced neutrophil chemoattractant (CINC), can be blocked by antibodies [61]. In a transient ischemic 
reperfusion stroke model, application of anti-CINC antibodies alleviated cerebral edema and reduced the infarct size 7 days after reperfusion [62].

CD 95L and tumor necrotic factor (TNF) interact with TNF receptor 1 and trigger apoptosis. As members of the cytokine family, they are involved in systematic inflammation. Humanized monoclonal antibodies specific for TNF were used in clinical practice to treat diseases such as rheumatoid arthritis and Crohn's disease [63]. These antibodies include infliximab (Remicade) from Centocor (Philadelphia, PA, US) and adalimumab (Humira) from Abbott (North Chicago, IL, US). TNF is involved in both innate and adaptive immune response after stroke [4]. TNF was found in the brain $30 \mathrm{~min}$ after MCAO [64] and its levels were increased early after transient ischemia attack [65]. Neutralization antibody against TNF was found to ameliorate brain damage in both permanent and reperfusion MCAO models $[66,67]$. When both TNF and CD95L were blocked by antibodies, an additive effect was observed on the reduction of the infarct volume after transient MCAO [68]. It is worthwhile to investigate whether infliximab or adalimumab could be helpful in stroke management, as they have already been proven safe in clinical practice.

\section{Side Effect, Safety, and Future Perspectives}

General side effects could arise from immunotherapy. Constitutional symptoms include transient low-grade fever, malaise, nausea, dyspnea, diarrhea, fatigue, hoarseness, palpitations, and headache. Aseptic meningitis could also occur due to a non-immune response triggered by formation of macro-aggregates or due to local inflammation caused by antibody interaction with endothelial antigens on the meningeal vessels. Other severe side effects include acute renal failure and anaphylaxis. It should be noted that thromboembolic events could occur with the increased plasma viscosity that develops after immunoglobulin infusion [69]. Myocardial infarction, pulmonary embolism, venous thrombosis, or even secondary stroke might occur. Animal experiments need to be carefully designed and evaluated to fully understand the possible side effects that may arise after immunotherapy.

The failure of clinical trials of Enlimomab provides valuable information on how to apply immunotherapy properly for stroke management. Preclinical studies on anti-ICAM-1 antibody showed beneficial effects in transient ischemic animal models but not in permanent stroke models [45-49]. However, the patients enrolled in the Enlimomab trial may not have reperfusion. Furthermore, Enlimomab is a murine monoclonal antibody, which triggered the patients' own immune responses [70]. Human anti-mouse antibody was found in patients receiving Enlimomab therapy [71], which could lead to an increased infection rate. Patients with fever generally had a poor outcome or died; such outcomes are not oddities in these trails. In animal models, stimulation of the self-immune system was observed with the activation of circulating neutrophilic granulocytes, increased $\beta 2$-integrin $\mathrm{CD} 11 \mathrm{~b}$, and $\mathrm{E}$ - and P-selectins. Additionally, ICAM-1 was upregulated by antiICAM-1 treatment $[72,73]$. To avoid the side effects from murine antibodies, humanized monoclonal antibodies were shown to be effective in treating other diseases without severe side effects [63].

Modern technology has greatly improved the production of high quality antibodies, including humanized antibodies, thus reducing the general side effects of immunotherapy. However, attention must be paid to several important factors throughout research for stroke immunotherapy. First, preclinical studies are performed on animals. Because the pathophysiology of stroke in humans and animal models is different, a comparison of the progression of stroke between species would help to improve the outcome of immunotherapy. Second, the target molecule should be chosen carefully. A molecule that is expressed highly in other tissues and has important functions should be targeted with caution, as severe side effects are more likely to occur. A deleterious molecule that is upregulated or expressed exclusively in the infarct region after stroke could be an ideal target for immunotherapy. Third, the stroke development is a dynamic process. Some molecules could play opposite roles during different phases of stroke. For example, blocking Nogo-A may be successful only at a later stage when neural regeneration occurs. Thus, choosing a time point for a particular immunotherapy is critical to avoid side effects. Fourth, because various molecules play different roles in stroke, a combination of multiple antibodies might achieve a better therapeutic outcome. Finally, current recanalization is effective in stroke management. Interaction of immunotherapy with current reperfusion methods needs to be carefully investigated to achieve a synergistic effect while avoiding antagonism.

In summary, numerous signaling pathways are altered after stroke insult. It is critical to determine the relative hierarchical importance, time course, and crosstalk among these signaling pathways to rationally plan targets for immunotherapy and points of intervention.

Acknowledgments This research is supported by the Singapore Ministry of Health's National Medical Research Council.

Conflict of Interest This article does not contain any studies with human or animal subjects. Chye Yun Yu, Gandi $\mathrm{Ng}$, and Ping Liao declare that they have no conflicts of interest.

Open Access This article is distributed under the terms of the Creative Commons Attribution License which permits any use, distribution, and reproduction in any medium, provided the original author(s) and the source are credited. 


\section{References}

1. Mellman I, Coukos G, Dranoff G. Cancer immunotherapy comes of age. Nature. 2011;480:480-9.

2. Iorio R, Lennon VA. Neural antigen-specific autoimmune disorders. Immunol Rev. 2012;248:104-21.

3. Villoslada P, Moreno B, Melero I, Pablos JL, Martino G, Uccelli A, et al. Immunotherapy for neurological diseases. Clin Immunol. 2008;128:294-305.

4. Iadecola C, Anrather J. The immunology of stroke: from mechanisms to translation. Nat Med. 2011;17:796-808.

5. Donnan GA, Davis SM. Stroke: expanded indications for stroke thrombolysis - what next? Nat Rev Neurol. 2012;8:482-3.

6. Yiu G, He Z. Glial inhibition of CNS axon regeneration. Nat Rev Neurosci. 2006;7:617-27.

7. Franklin RJ, Ffrench-Constant C, Edgar JM, Smith KJ. Neuroprotection and repair in multiple sclerosis. Nat Rev Neurol. 2012;8:624-34.

8. GrandPre T, Nakamura F, Vartanian T, Strittmatter SM. Identification of the Nogo inhibitor of axon regeneration as a reticulon protein. Nature. 2000;403:439-44.

9. Fournier AE, GrandPre T, Strittmatter SM. Identification of a receptor mediating Nogo-66 inhibition of axonal regeneration. Nature. 2001;409:341-6.

10. Caroni P, Schwab ME. Antibody against myelin-associated inhibitor of neurite growth neutralizes nonpermissive substrate properties of CNS white matter. Neuron. 1988;1:85-96.

11. Seymour AB, Andrews EM, Tsai SY, Markus TM, Bollnow MR, Brenneman MM, et al. Delayed treatment with monoclonal antibody IN-1 1 week after stroke results in recovery of function and corticorubral plasticity in adult rats. J Cereb Blood Flow Metab. 2005;25:1366-75.

12. Tsai SY, Markus TM, Andrews EM, Cheatwood JL, Emerick AJ, Mir AK, et al. Intrathecal treatment with anti-Nogo-A antibody improves functional recovery in adult rats after stroke. Exp Brain Res. 2007:182:261-6.

13. Tsai SY, Papadopoulos CM, Schwab ME, Kartje GL. Delayed antiNogo-a therapy improves function after chronic stroke in adult rats. Stroke. 2011;42:186-90.

14. Papadopoulos CM, Tsai SY, Cheatwood JL, Bollnow MR, Kolb BE, Schwab ME, et al. Dendritic plasticity in the adult rat following middle cerebral artery occlusion and Nogo-a neutralization. Cereb Cortex. 2006;16:529-36.

15. Papadopoulos CM, Tsai SY, Alsbiei T, O’Brien TE, Schwab ME, Kartje GL. Functional recovery and neuroanatomical plasticity following middle cerebral artery occlusion and $\mathrm{IN}-1$ antibody treatment in the adult rat. Ann Neurol. 2002;51:433-41.

16. Wiessner C, Bareyre FM, Allegrini PR, Mir AK, Frentzel S, Zurini $\mathrm{M}$, et al. Anti-Nogo-A antibody infusion 24 hours after experimental stroke improved behavioral outcome and corticospinal plasticity in normotensive and spontaneously hypertensive rats. J Cereb Blood Flow Metab. 2003;23:154-65.

17. Gillani RL, Tsai SY, Wallace DG, O'Brien TE, Arhebamen E, Tole $\mathrm{M}$, et al. Cognitive recovery in the aged rat after stroke and antiNogo-A immunotherapy. Behav Brain Res. 2010;208:415-24.

18. Ma J, Tian WM, Hou SP, Xu QY, Spector M, Cui FZ. An experimental test of stroke recovery by implanting a hyaluronic acid hydrogel carrying a Nogo receptor antibody in a rat model. Biomed Mater. 2007;2:233-40.

19. Kilic E, ElAli A, Kilic U, Guo Z, Ugur M, Uslu U, et al. Role of Nogo-A in neuronal survival in the reperfused ischemic brain. $\mathrm{J}$ Cereb Blood Flow Metab. 2010;30:969-84.

20. Irving EA, Vinson M, Rosin C, Roberts JC, Chapman DM, Facci L, et al. Identification of neuroprotective properties of anti-MAG antibody: a novel approach for the treatment of stroke? J Cereb Blood Flow Metab. 2005;25:98-107.
21. Derfuss T, Meinl E. Identifying autoantigens in demyelinating diseases: valuable clues to diagnosis and treatment? Curr Opin Neurol. 2012;25:231-8

22. Frenkel D, Huang Z, Maron R, Koldzic DN, Hancock WW, Moskowitz MA, et al. Nasal vaccination with myelin oligodendrocyte glycoprotein reduces stroke size by inducing IL-10-producing CD4+ T cells. J Immunol. 2003;171:6549-55.

23. The National Institute of Neurological Disorders and Stroke rt-PA Stroke Study Group. Tissue plasminogen activator for acute ischemic stroke. N Engl J Med. 1995;333:1581-7.

24. Nicole O, Docagne F, Ali C, Margaill I, Carmeliet P, MacKenzie ET, et al. The proteolytic activity of tissue-plasminogen activator enhances NMDA receptor-mediated signaling. Nat Med. 2001;7:5964.

25. During MJ, Symes CW, Lawlor PA, Lin J, Dunning J, Fitzsimons $\mathrm{HL}$, et al. An oral vaccine against NMDAR1 with efficacy in experimental stroke and epilepsy. Science. 2000;287:1453-60.

26. Benchenane K, Castel H, Boulouard M, Bluthe R, FernandezMonreal M, Roussel BD, et al. Anti-NR1 N-terminal-domain vaccination unmasks the crucial action of tPA on NMDA-receptormediated toxicity and spatial memory. J Cell Sci. 2007;120:578-85.

27. Macrez R, Obiang P, Gauberti M, Roussel B, Baron A, Parcq J, et al. Antibodies preventing the interaction of tissue-type plasminogen activator with $N$-methyl-D-aspartate receptors reduce stroke damages and extend the therapeutic window of thrombolysis. Stroke. 2011;42: 2315-22.

28. Macrez R, Bezin L, Le Mauff B, Ali C, Vivien D. Functional occurrence of the interaction of tissue plasminogen activator with the NR1 subunit of $N$-methyl-D-aspartate receptors during stroke. Stroke. 2010;41:2950-5.

29. Muir KW. Glutamate-based therapeutic approaches: clinical trials with NMDA antagonists. Curr Opin Pharmacol. 2006;6:53-60.

30. Dalmau J, Lancaster E, Martinez-Hernandez E, Rosenfeld MR, Balice-Gordon R. Clinical experience and laboratory investigations in patients with anti-NMDAR encephalitis. Lancet Neurol. 2011;10:63-74.

31. Hughes EG, Peng X, Gleichman AJ, Lai M, Zhou L, Tsou R, et al. Cellular and synaptic mechanisms of anti-NMDA receptor encephalitis. J Neurosci. 2010;30:5866-75.

32. Matsuo Y, Kihara T, Ikeda M, Ninomiya M, Onodera H, Kogure K. Role of neutrophils in radical production during ischemia and reperfusion of the rat brain: effect of neutrophil depletion on extracellular ascorbyl radical formation. J Cereb Blood Flow Metab. 1995; 15:941-7.

33. Matsuo Y, Onodera H, Shiga Y, Nakamura M, Ninomiya M, Kihara $\mathrm{T}$, et al. Correlation between myeloperoxidase-quantified neutrophil accumulation and ischemic brain injury in the rat. Effects of neutrophil depletion. Stroke. 1994;25:1469-75.

34. Zhang R, Chopp M, Zhang Z, Jiang N, Powers C. The expression of $\mathrm{P}$ - and E-selectins in three models of middle cerebral artery occlusion. Brain Res. 1998;785:207-14.

35. Suzuki H, Abe K, Tojo SJ, Kitagawa H, Kimura K, Mizugaki M, et al. Reduction of ischemic brain injury by anti-P-selectin monoclonal antibody after permanent middle cerebral artery occlusion in rat. Neurol Res. 1999;21:269-76.

36. Suzuki H, Hayashi T, Tojo SJ, Kitagawa H, Kimura K, Mizugaki M, et al. Anti-P-selectin antibody attenuates rat brain ischemic injury. Neurosci Lett. 1999;265:163-6.

37. Huang J, Choudhri TF, Winfree CJ, McTaggart RA, Kiss S, Mocco J, et al. Postischemic cerebrovascular E-selectin expression mediates tissue injury in murine stroke. Stroke. 2000;31:3047-53.

38. Ishibashi S, Maric D, Mou Y, Ohtani R, Ruetzler C, Hallenbeck JM. Mucosal tolerance to E-selectin promotes the survival of newly generated neuroblasts via regulatory T-cell induction after stroke in spontaneously hypertensive rats. J Cereb Blood Flow Metab. 2009;29:606-20. 
39. Takeda H, Spatz M, Ruetzler C, McCarron R, Becker K, Hallenbeck $\mathrm{J}$. Induction of mucosal tolerance to E-selectin prevents ischemic and hemorrhagic stroke in spontaneously hypertensive genetically strokeprone rats. Stroke. 2002;33:2156-63.

40. Yenari MA, Sun GH, Kunis DM, Onley D, Vexler V. L-selectin inhibition does not reduce injury in a rabbit model of transient focal cerebral ischemia. Neurol Res. 2001;23:72-8.

41. Bednar MM, Gross CE, Russell SR, Fuller SP, Ellenberger CL, Schindler E, et al. Humanized anti-L-selectin monoclonal antibody DREG200 therapy in acute thromboembolic stroke. Neurol Res. 1998;20:403-8.

42. Rieckmann P, Nunke K, Burchhardt M, Albrecht M, Wiltfang J, Ulrich M, et al. Soluble intercellular adhesion molecule-1 in cerebrospinal fluid: an indicator for the inflammatory impairment of the blood-cerebrospinal fluid barrier. J Neuroimmunol. 1993;47:13340 .

43. Smith CW, Marlin SD, Rothlein R, Toman C, Anderson DC. Cooperative interactions of LFA-1 and Mac-1 with intercellular adhesion molecule- 1 in facilitating adherence and transendothelial migration of human neutrophils in vitro. J Clin Invest. 1989;83:2008-17.

44. Frijns CJ, Kappelle LJ. Inflammatory cell adhesion molecules in ischemic cerebrovascular disease. Stroke. 2002;33:2115-22.

45. Bowes MP, Zivin JA, Rothlein R. Monoclonal antibody to the ICAM-1 adhesion site reduces neurological damage in a rabbit cerebral embolism stroke model. Exp Neurol. 1993;119:215-9.

46. Chopp M, Li Y, Jiang N, Zhang RL, Prostak J. Antibodies against adhesion molecules reduce apoptosis after transient middle cerebral artery occlusion in rat brain. J Cereb Blood Flow Metab. 1996;16:578-84.

47. Zhang RL, Chopp M, Li Y, Zaloga C, Jiang N, Jones ML, et al. AntiICAM-1 antibody reduces ischemic cell damage after transient middle cerebral artery occlusion in the rat. Neurology. 1994;44:1747-51.

48. Bowes MP, Rothlein R, Fagan SC, Zivin JA. Monoclonal antibodies preventing leukocyte activation reduce experimental neurologic injury and enhance efficacy of thrombolytic therapy. Neurology. 1995; 45:815-9.

49. Zhang RL, Chopp M, Jiang N, Tang WX, Prostak J, Manning $\mathrm{AM}$, et al. Anti-intercellular adhesion molecule-1 antibody reduces ischemic cell damage after transient but not permanent middle cerebral artery occlusion in the Wistar rat. Stroke. 1995;26:1438-42.

50. Enlimomab Acute Stroke Trial Investigators. Use of anti-ICAM-1 therapy in ischemic stroke: results of the Enlimomab Acute Stroke Trial. Neurology. 2001;57:1428-34.

51. Jaeschke H, Farhood A, Bautista AP, Spolarics Z, Spitzer JJ, Smith CW. Functional inactivation of neutrophils with a Mac-1 (CD11b/ CD18) monoclonal antibody protects against ischemia-reperfusion injury in rat liver. Hepatology. 1993;17:915-23.

52. Simpson PJ, Todd 3rd RF, Fantone JC, Mickelson JK, Griffin JD, Lucchesi BR. Reduction of experimental canine myocardial reperfusion injury by a monoclonal antibody (anti-Mo1, anti-CD11b) that inhibits leukocyte adhesion. J Clin Invest. 1988;81:624-9.

53. Simpson PJ, Todd 3rd RF, Mickelson JK, Fantone JC, Gallagher KP, Lee KA, et al. Sustained limitation of myocardial reperfusion injury by a monoclonal antibody that alters leukocyte function. Circulation. 1990;81:226-37.

54. Chen H, Chopp M, Zhang RL, Bodzin G, Chen Q, Rusche JR, et al. Anti-CD11b monoclonal antibody reduces ischemic cell damage after transient focal cerebral ischemia in rat. Ann Neurol. 1994; 35:458-63.

55. Chopp M, Zhang RL, Chen H, Li Y, Jiang N, Rusche JR. Postischemic administration of an anti-Mac-1 antibody reduces ischemic cell damage after transient middle cerebral artery occlusion in rats. Stroke. 1994;25:869-75.
56. Bednar MM, Wright SD, Raymond-Russell SJ, Kohut JJ, Gross CE. IB4, a monoclonal antibody against the CD18 leukocyte adhesion protein, reduces intracranial pressure following thromboembolic stroke in the rabbit. Neurol Res. 1996;18:171-5.

57. Colditz I, Zwahlen R, Dewald B, Baggiolini M. In vivo inflammatory activity of neutrophil-activating factor, a novel chemotactic peptide derived from human monocytes. Am J Pathol. 1989;134:755-60.

58. Huber AR, Kunkel SL, Todd 3rd RF, Weiss SJ. Regulation of transendothelial neutrophil migration by endogenous interleukin-8. Science. 1991;254:99-102.

59. Al-Bahrani A, Taha S, Shaath H, Bakhiet M. TNF-alpha and IL-8 in acute stroke and the modulation of these cytokines by antiplatelet agents. Curr Neurovasc Res. 2007;4:31-7.

60. Kostulas N, Pelidou SH, Kivisakk P, Kostulas V, Link H. Increased IL-1beta, IL-8, and IL-17 mRNA expression in blood mononuclear cells observed in a prospective ischemic stroke study. Stroke. 1999;30:2174-9.

61. Wittwer AJ, Carr LS, Zagorski J, Dolecki GJ, Crippes BA, De Larco JE. High-level expression of cytokine-induced neutrophil chemoattractant (CINC) by a metastatic rat cell line: purification and production of blocking antibodies. J Cell Physiol. 1993;156: $421-7$.

62. Yamasaki Y, Matsuo Y, Zagorski J, Matsuura N, Onodera H, Itoyama $\mathrm{Y}$, et al. New therapeutic possibility of blocking cytokine-induced neutrophil chemoattractant on transient ischemic brain damage in rats. Brain Res. 1997;759:103-11.

63. Bachmann MF, Dyer MR. Therapeutic vaccination for chronic diseases: a new class of drugs in sight. Nat Rev Drug Discov. 2004;3:81-8.

64. Buttini M, Appel K, Sauter A, Gebicke-Haerter PJ, Boddeke HW. Expression of tumor necrosis factor alpha after focal cerebral ischaemia in the rat. Neuroscience. 1996;71:1-16.

65. Saito K, Suyama K, Nishida K, Sei Y, Basile AS. Early increases in TNF-alpha, IL-6 and IL-1 beta levels following transient cerebral ischemia in gerbil brain. Neurosci Lett. 1996;206:149-52.

66. Lavine SD, Hofman FM, Zlokovic BV. Circulating antibody against tumor necrosis factor-alpha protects rat brain from reperfusion injury. J Cereb Blood Flow Metab. 1998;18:52-8.

67. Meistrell 3rd ME, Botchkina GI, Wang H, Di Santo E, Cockroft KM, Bloom $\mathrm{O}$, et al. Tumor necrosis factor is a brain damaging cytokine in cerebral ischemia. Shock. 1997;8:341-8.

68. Martin-Villalba A, Hahne M, Kleber S, Vogel J, Falk W, Schenkel J, et al. Therapeutic neutralization of CD95-ligand and TNF attenuates brain damage in stroke. Cell Death Differ. 2001;8:679-86.

69. Dalakas MC. High-dose intravenous immunoglobulin and serum viscosity: risk of precipitating thromboembolic events. Neurology. 1994;44:223-6.

70. Cosimi AB, Conti D, Delmonico FL, Preffer FI, Wee SL, Rothlein R, et al. In vivo effects of monoclonal antibody to ICAM-1 (CD54) in nonhuman primates with renal allografts. J Immunol. 1990;144: 4604-12.

71. Schneider D, Berrouschot J, Brandt T, Hacke W, Ferbert A, Norris $\mathrm{SH}$, et al. Safety, pharmacokinetics and biological activity of enlimomab (anti-ICAM-1 antibody): an open-label, dose escalation study in patients hospitalized for acute stroke. Eur Neurol. 1998;40:78-83.

72. Furuya K, Takeda H, Azhar S, McCarron RM, Chen Y, Ruetzler CA, et al. Examination of several potential mechanisms for the negative outcome in a clinical stroke trial of enlimomab, a murine anti-human intercellular adhesion molecule-1 antibody: a bedside-to-bench study. Stroke. 2001;32:2665-74.

73. Vuorte J, Lindsberg PJ, Kaste M, Meri S, Jansson SE, Rothlein R, et al. Anti-ICAM-1 monoclonal antibody R6.5 (Enlimomab) promotes activation of neutrophils in whole blood. J Immunol. 1999; $162: 2353-7$. 